\title{
The mediating role of general self-efficacy on the relationship between culture and communication behavior of Syrians
}

\author{
Reem M. Ramadan
}

\begin{abstract}
This study analyses the role general self-efficacy plays within the relationship between culture and communication behavior in an unstudied Arab culture; Syria. Participants were 402 undergraduate students at Damascus University. General self-efficacy mediated the relationship between culture and touch, eye contact, gestures, paralinguistics, facial expressions, interpersonal distance and tolerance for disagreement. Thus, indicating that perceptions of 'the self' reduces the impact of culture on individual behavior. Results from this study could help for the better understanding of Arab communication behavior and for the increase of the generalizability of theories developed in Western societies.
\end{abstract}

Keywords- Communication; GSE; Collectivism; Individualism; Syrian Arabs.

\section{INTRODUCTION}

In response to global conditions, Shutter (1990) called for a need to explore communicative patterns in unstudied societies worldwide. Till date most of the work on communication research has been conducted in settings outside the Arab world (Marsh, Hau, \& Kong, 2002). According to Triandis (1996), psychological theories are mostly built based on unexamined cultural assumptions. Even though self-efficacy proved to be a strong predictor of performance within Western populations, it is understudied in $70 \%$ of humans in non-Western cultures and little is known about how self-efficacy beliefs operate within such cultures (Triandis, 1995). Evidence suggests that selfefficacy beliefs have similar effects across cultures (Bandura, 1995). However, the link between culture and self-efficacy beliefs has yet to be made empirically (Oettingen, 1995). Therefore, there is a need for a "Culturally attentive" educational psychology that explores human functioning in wide areas of social and cultural contexts (Pajares, 2000). The main purpose of this study is to examine the impact of national culture on individual behavior and for the mediating effect of general self-efficacy beliefs in shaping behavior. Results from this study could help in the further and better understanding of Arab communication behavior.

Management Department - Damascus University Syria

\author{
Rebecca S. Merkin
}

\section{WHAT IS ARAB?}

Arab is not a nationality, religion or race (Almaney \& Alwan, 1982). The term "Arab" has synonymously been misused with the "Muslim World" and the "Middle East". Defining culture based on geographic or group members could lead to misunderstanding when relying solely on national identity or regional groupings (Collier, 1989; Collier \& Thomas, 1988). Although Arab countries are regarded Middle Eastern, not all Middle Eastern countries are Arab. 85-90\% of the Arab population is Muslim (Kimball, 1984), and only $15 \%$ of the world's Muslims are Arabs (EENI, 2015). Patai (1983, p.11) described the boundaries of the Arab world 'to the north and east, the Arab world borders on the non-Arab Muslim Middle Eastern countries of Turkey, Iran, Afghanistan, and Pakistan; while to the south, in Africa, the Arab world gradually gives way to the non-Arab Muslim Middle Eastern areas of the Saharan and Sudanic countries'.

Another misleading stereotyping of groups in the Arab world region is that Arab countries are similar in terms of predominant cultural attitudes and behaviors (e.g., the Arabian Peninsula; Bahrain, Kuwait, Oman, Qatar, Saudi Arabia, United Arab Emirates and Yemen are different from Arabs in the Fertile Crescent; Iraq, Jordan, Lebanon, Palestine, and Syria). In another example, members of the Arab Christian Maronite community in Lebanon are strikingly different from Saudi Arabian Muslims in attitudes, behaviors, and general lifestyle (Feghali, 1997). Although it is beyond the scope of this study, Islam has a very strong influence on the daily lives of both Arab Muslims and non-Muslims (Lippman, 1990; Martin, 1982; Mostyn \& Hourani, 1988; Rugh, 1986).

\section{THEORETICAL FOUNDATION AND HYPOTHESES}

Individual behavior can be viewed as a mixture of personal and behavioral environmental factors. Although integrating psychological theories with culture is regarded as "an abstract, disputed, and inherently irresolvable process' (Cooper \& Denner, 1998, p. 563), it is critical for the understanding of individuals in societies and to theory building. The theoretical foundation for this paper is grounded in the theory of culture by Hofstede (1980), the implicit communication theory by Albert Mehrabian (1969), and Albert Bandura's (1986) social cognitive theory of human development. 


\section{A. Culture}

Hofstede's defines culture (1980, p.25) as the 'collective programming of the mind which distinguishes the member of one human group from another.' Values constitute the differences in cultures (Inkeles \& Levinson, 1969). The environment is responsible for shaping personalities in a way that makes individuals think and behave differently from others who do not share with them the same norms, values, and ideas (Minggang \& Yuan, 2004). The Arab region is characterized as situation-centeredness where individual needs are sacrificed for one's own extended family and larger in-group (Nydell, 1987; Yousef, 1974). Communal cohesion is 'undoubtedly the most desired value within Arabs' value system' (Khalid, 1977, p.127). Past studies failed to address basic Arab values. Moreover, the role of context has not been adequately addressed in cultural studies (Mishler, 1979). Individuals perceive national cultural values to differing degrees (Hofstede, 1984). In fact, an individual may belong to many cultural groups at the same time and possess multiple cultural identities (Straub, Loch, Evaristo, Karahanna \& Srite, 2002). Social identity presupposes an individual is consciously aware of belonging to a group while cultural identity does not (Deaux, 1993). Therefore, 'an in situ measurement of culture is more appropriate' (Straub et al, 2002, p. 20) to examine the impact of national culture on individual behavior. Culture can only manifest itself through the individual and then be aggregated to the collective. Therefore, assessing an individual's perceived cultural values is more appropriate and meaningful for predicting individual behavior. According to Hofstede (1980) Syria is a highly collectivist culture.

\section{B. Communication behavior}

The implicit communication theory states that messages between individuals are transmitted through verbal and nonverbal communication referred to as immediacy. Non-verbal immediacy defined by Mehrabian (1969) are those communication behaviors that 'enhance closeness to and nonverbal interaction with another' (p.203). Mehrabian acknowledges that 'implicit communication deals primarily with the transmission of information about feelings and likedislike or attitudes' (Mehrabian, 1981, p.3). Implicit communication includes body position and movement, eye contact and physical proximity (Richmond, Gorham \& McCroskey, 1987).

\section{1) Arab verbal communication behavior}

Native Arabic speakers share common features of communication behavior (Cohen, 1987; Gudykunst \& Toomey, 1988; Suleiman, 1973). 2.2.1.1 Indirectness; refers to concealing actual wants, needs, or goals during discourse (Gudykunst \& Ting-Toomey, 1988). While research supports the indirectness of Arabs, other studies by Nelson, El-Bakary \& Al-Balal (1993) found that Egyptians use both direct and indirect communication behavior depending on context, and complement each other directly.

- Elaborateness; is the rich and expressive language use due to that Arabs tend to establish credibility during interaction, therefore, they use both exaggeration and assertion (Patai, 1983; Shouby, 1951). The base for
Arabs argumentation is the persuasive presentation of the idea, not the logic or proof behind the idea itself (Koch, 1983).

- Paralinguistics; few empirical studies explored the paralinguistics of Arab cultures. Arabs are relatively loud and tend to speak fast (Samovar \& Porter, 1991). To Arabs, loudness resembles strength and sincerity while a soft tone implies weakness and in some cases deviousness (Gudykunst \& Kim, 1984). The higher pitch range of Arabs is somewhat regarded as aggressive or threatening by English speakers. However, the transfer of preferred patterns of intonation by Arabs when speaking foreign languages may send unwanted negative meaning in English. Therefore English speakers may be able to distinguish between agreement and disagreement behavior, and warnings based on intonation (Safadi \& Valentine, 1990).

\section{2) Arab nonverbal communication patterns}

- Gestures; are the 'subtle physical differences that amount to great semantic variations' (Safadi \& Valentine, 1990, p.278). An Arab specialist documented around 247 separate gestures Arabs use to accompany their speech (Samovar \& Porter, 1991).

- Eye contact; contrary to the indirect verbal communication patterns, Arabs tend to gaze more directly at their partners (Hall, 1966; Watson \& Graves, 1966). Interactions between Arabs tend to be direct in body and eye contact especially between those of the same-sex. This behavior emphasizes truthfulness and reciprocates interest (Watson, 1970; Watson \& Graves, 1966). From another perspective, religious individuals tend to avoid direct eye contact, especially with strangers as a sign of consent.

- Touch; According to Hall's (1966) proxemic theory, Arab societies are 'contact cultures'. However, touching between individuals from the opposite sex is considered extremely offensive especially among people from the Arabian Peninsula. The Arab social code in general forbids any intimacy display between opposite sexes including any gestures of affection (Nydell, 1987).

- Interpersonal distance; Hall (1966, 1973) contents that people from all cultures distinguish between four levels of interpersonal space depending on the social relationship in place: intimate, personal, social, and public. However, they differ in the space they attribute to each relationship. According to Hall (1966) Arabs gain their privacy through psychological separation related to the inseparable relationship between the public and private self, contrary to Americans who distinguish between the mind and body. In general, Arab males have more direct, confrontational types of body orientations, they tend to sit closer to each other (Watson \& Graves, 1966). Members of Arab cultures tend to divide people into friends and strangers (Nydell, 1987). Sanders, Hakky \& Brizzolara (1985) 
explored personal space among Egyptians and Americans; both cultural groups kept a further distance with strangers than with friends, and both sample sexes kept male strangers farther than female strangers with Egyptian females keeping the same distance with both male friends and strangers, this behavior is expected to be manifested among the more traditional and conservative Arabs. However, Lomeranz (1976) in a study of interaction distances of Iraqi, Argentinian and Russian students found significant differences within samples of contact cultures indicating the need to redefine and further differentiate cultural concepts.

- Facial expression of emotions; studies supported the universality of emotions reflected in six facial expressions: anger, disgust, fear, happiness, sadness, and surprise (Ekman, 1973; Ekman \& Friesen, 1969, Izard, 1971). When facial expressions are used as markers in the brain activity and nerves, there is evidence of similarity in the physiological responses to emotions among widely divergent cultures (Davidson, 2003; Levenson, Ekman, Heider, \& Friesen, 1992; Tsai \& Levenson, 1997). Despite this, studies found people tend to express their emotions differently. Ekman and Friesen (1969) introduced the term cultural display rules to explain cultural differences in facial expressions of emotion among individuals. These rules are learnt in childhood and can be modified depending on certain social conditions. Ekman and Friesen (1969, 1975) described six different ways for managing expressions when emotions are aroused; amplification/deamplification (e.g., feelings of sadness or happiness), concealing, neutralizing, combining emotions (e.g., when feelings of sadness are mixed with a smile). Matsumoto, Yoo, Hirayama \& Petrova (2005) acknowledged these differences to be a result of personality differences in which expression regulation occurs in different ways, and is not a simple expression-suppression dimension. Matsumoto (1989) found individualism to be positively correlated with perceived rates of negative emotions and predicted emotion recognition levels to be better in individualistic cultures that encourage free expression of emotions, thereby promoting a more accurate judgment of emotions. However, research that attempted to test emotion recognition of in-groups reached mixed results (Boucher \& Carlson, 1980; Kilbride \& Yarczower, 1983; Markham \& Wang, 1996). Other studies supported the in-group hypothesis (Elfenbein \& Ambady, 2003).

- Tolerance for Disagreement; 'people with a high tolerance for disagreement (TFD) are relatively conflict resistant whereas, people with a low tolerance for disagreement are highly conflict prone' (McCorskey, 1992, p.172). The earlier tolerance for disagreement that emerged from scholars distinguished between positive and negative conflict (Burgon, Heston \& McCroskey, 1974). However, individuals vary in their perceptions of when a disagreement turns to become conflict. Therefore, tolerance for disagreement was redefined as 'the amount of disagreement an individual can tolerate before he or she perceives the existence of conflict in a relationship' (Richmond \& McCroskey, 1992, p.125). The tolerance for disagreement term was reconceptualized to indicate differences in opinions between two individuals with no intention of negative sentiments (McCroskey \& Wheeless, 1976). In low-context cultures, individuals can differentiate between the conflict issue and the person involved in the conflict, and individuals tend to express more direct and explicit behavior when dealing with conflict. Research revealed that individuals in high-context cultures avoid instigating conflict. Moreover, they tend to deny that conflict even exists (Neuliep, 2009).

\section{Self-efficacy}

Bandura (1994, p.71) defined self-efficacy as 'people's beliefs about their capabilities to produce designated levels of performance that exercise influence over events that affect their lives.' These beliefs are the determinants of how people think, feel, and behave in a specific situation (Bandura, 1997). Based on Albert Bandura's (1986) social cognitive theory of human development, individual behavior can be viewed as a mixture of personal and behavioral environmental factors. Human agency theories state that all individuals share the same basic psychological virtues where self-efficacy is among them, and is universally inherited in all people (Bandura, 2002). The social cognitive structure of an individual is the result of the interdependence nature of three factors (a) personal factors in the form of cognition (b) behavior, and (c) environmental influences. These factors interact with each other resulting in triadic reciprocality which may vary according to circumstances, individuals and activities (Bandura, 1986). Individuals' beliefs of personal competence 'touch, at least to some extent, most everything they do and perceived selfefficacy will usurp the lion's share of the variance in human conduct' (Bandura, 1984, p.251- 252). Thus, efficacy conviction is a major determinant for initiating behavior, choice of activities, and effort (Bandura, 1977). Studies that investigated the concept of self-efficacy found that perceived self-efficacy helps individuals to achieve pre-set goals, recover from setbacks, feel, think, act, challenge tasks, deal effectively with unforeseen circumstances, and cope successfully with life in new situations (Armitage, Conner, Loach \& Willets, 1999; Fan \& Mak, 1998; Griffiths, 2007; Kim \& Omizo, 2005; Klassen, 2004; Kumar \& Lal, 2006; Luszczynska \& Schwarzer, 2005; Scholz et al, 2002; Schwarzer \& Fuchs, 1996; Schwarzer \& Jerusalem, 1995). High efficacious individuals tend to behave impassively, use active approaches to different situations, express less anxiety, and reveal constructive emotions in threatening situations, are more capable of mobilizing resources, devote more time and effort, and persist longer when tackling unforeseen situations (Bandura, 1995; 1997). Self-efficacy is developed from four information sources; mastery experience is when past successes of individuals' strengthen their perceived feelings of self-efficacy and failures weakens it, social modeling regarding 'others' successes' contribute to raising an individual's feeling of selfefficacy to succeed in similar activities, social persuasion is 
where receiving verbal encouragement from others persuades individuals to believe that they have the ability to succeed too. The last source is the individual's psychological reaction to certain situations (Bandura, 1977, 1986). Self-efficacy can be improved through training and modeling and can be changed as a result of learning, past experience and feedback received from others (Gist and Mitchell, 1992). Behavioral capabilities can be enhanced through modeling which in turn translates behavioral conceptions to appropriate actions, and makes individuals approach situations based on self-perceived capabilities (Bandura, 1971; Flanders, 1968). According to (Bandura, 1986, 1997) the predictive power of self-efficacy beliefs differ according to the task under prediction. Selfefficacy judgments are regarded as excellent predictors of choice and behavioral direction.

\section{Self-efficacy and culture}

Past studies by (Schwarzer and Born, 1997), and (Scholz et al, 2002) found that the perceived GSE a unidimensional and universal construct that has an explanatory and predictive dimension making it applicable to different research domains. Studies found that an individual's confidence in coping abilities is of a global nature (Schwarzer \& Jerusalem, 1995; Skinner, Chapman \& Baltes, 1988). However, how individuals perceive their own efficacy is developed and derived from the value system which is influenced by several different environmental factors in a given culture (Inkeles \& Levinson, 1969). Personal efficacy expectations do not operate as dispositional determinants independently of contextual factors (Bandura, 1977). Within the origins of the self-efficacy theory, the social learning theory acknowledges that self-efficacy is a result of diverse sources of information that is conveyed through direct and mediated experience. However, the effectance theory acknowledges that the effectance drive is a result of prolonged transactions with an individual's surroundings and is an intristic drive for transactions with the environment. These differences in theoretical approaches have significant implications for how one goes about studying the role of perceived self-efficacy in behavioral contexts (Bandura, 1969, 1977). Biglan (1987) criticized Bandura's self-efficacy theory for not accounting for the role the environment plays in determining behavior. Whereby self-efficacy affects overt behavior, behavior analysts prefer to include environmental variables (Biglan \& Kass, 1977; Moore, 1984a, 1984b; Skinner, 1953; Zettle \& Hayes, 1982). Behavioral analysts regard the environment as a critical factor in the determination of thoughts and statements of efficacy as well as verbal and non-verbal behavior and physiological responses (Biglan, 1987). The self-phenomena, described by the cultural dimensions of independence/ interdependence and individualism/collectivism concepts applied to individuals, termed as idiocentrism and allocentrism respectively, refer to the degree of separateness and connectedness of individuals and groups (Markus \& Kitayama, 1991; Triandis, 1995, 2001). This may assume a different form according to the culturally influenced relationship of self with others. Individuals with an independent self-construals regard themselves as autonomous from the surrounding physical and social environments where there is a disconnection between the self and others. In contrast, individuals with an interdependent self construals do not differentiate between the self and others. The self is defined according to social contexts and has meaning when connected to others, and the sharing of beliefs and behaviors of others is essential to their survival (Markus \& Kitayama, 1991). Bandura (1997, 2002) rejects the notion that self-efficacy plays a less important role in collectivist cultures "people live their lives neither entirely autonomously nor entirely interdependently in any society. Interdependence does not obliterate a personal self '(Bandura, 1997, p.32). Furthermore, he found self-efficacy to be as important for collectivist's cultures as it is for individualist's cultures and points out that individuals in collective settings adjust their behavior depending on the context and that groups within the collectivis dimension vary greatly (Bandura, 1997, 2002). Considerable variation exists within cultural groups and even within individuals with regards to changing settings and contexts (Sinha \& Tripathi, 1994). However, with in-group members, collectivists display a high level of communalism than with out-group members where they behave differently. Culture may play an influential role in forming beliefs of personal efficacy within the appraisal process that personal self-efficacy goes through; selecting, weighting, and integrating information from multiple sources. Therefore, it may affect the type and source of selected information and how it is weighted and integrated in self-efficacy judgments (Oettingen, 1995). Furthermore, the independent self-construal is a significant factor positively predicting self-efficacy within personal, social and cultural factors (Cho, So \& Lee, 2009). Numerous scholars and theorists argued that the evaluative nature of self-beliefs make them play the role of a filter or a mediator for subsequent behavior, and a filter for interpreting new phenomena, where an individual's judgment of own self efficacy mediates the effects of other determinants of behavior (Abelson, 1979; Calderhead \& Robson, 1991; Dewey, 1993; Goodman, 1988; James, 1988; Mead, 1982; Nisbett \& Ross, 1980; Pajares, 1992).

Based on the above discussions the following hypothesis is proposed:

$\mathrm{H}: 1$. Individuals who perceive an independent selfconstrual will exert a lower behavioral effect on touch, eye contact, gestures, paralinguistics, facial expressions, interpersonal distance and tolerance for disagreement than individuals who perceive an interdependent self-construal within the same culture.

Self-efficacy beliefs are both task and situation specific, and are contextual. Consequently they are assessed at a more micro analytic level. They also influence the amount of stress and anxiety an individual experiences while engaging in a behavior (Pajares, 1996). General self-efficacy measures the general sense of efficacy, when used, self-efficacy becomes a generalized personality trait rather than a context-specific judgment (Pajares, 1996). Central to self-efficacy is the self rather than the other, therefore general self-efficacy is theorized to mediate the impact of the interdependent self-construal and the independent self-construal on individual communication behavior of individuals within a collectivist culture. Therefore, it is proposed that; 
H: 2. General Self Efficacy will mediate the effect of the independent self-construal found in $\mathrm{H}: 1$.

H: 3. General Self Efficacy will mediate the effect of the interdependent self-construal found in $\mathrm{H}$ : 1 .

\section{METHOD}

\section{A. Study participants}

Data were collected from 420 undergraduate students at Damascus University using the random sampling method. The first phase resulted in 264 usable responses, and the second phase resulted in 138 usable responses, $\mathrm{N}=402$ (210 males; $52.24 \%, 192$ female; 47.76\%; $\mathrm{M}$ age $=21$, SD age $=2.25$ ). Nonresponse bias regarding gender was assessed through examining the demographic data as to whether the respondents were representative of the study population. The demographic statistics for the sample did not differ significantly from the University population as a whole (males, 54.40\%; females, $45.60 \%$ ). No other demographic information was collected.

\section{B. Instrumentation}

In order to contextualize the questions, students were asked at the beginning of the questionnaire to think of how they would react if they encountered a similar situation. Scales were modified and used to measure the constructs of the study (1) The GSE Scale by (Scholz et al, 2002) was used to measure the GSE construct. Self-efficacy in this study is regarded as a generalized personality trait rather than a context-specific judgment (Pajares, 1996); (2) The Tolerance for disagreement scale (TFD) by Teven, McCroskey and Richmond (1998) was used to measure an individual's preference to avoid disagreement; (3) The independent/ interdependent selfconstrual cultural variables were measured using Leung and Kim's (1997) Self-Construal Scale ; (4) The Nonverbal Immediacy Scale (NIS) by Richmond, McCroskey, and Johnson (2003) was used to extract constructs related to paralinguistics, touch and interpersonal distance, gestures, direct eye contact and facial expression of emotions. All answers were on a Likert-type scale with a 5-point variation, ranging from $1=$ strongly disagree and $5=$ strongly agree. Items that were negatively phrased were reverse coded, 5= strongly disagree and $1=$ strongly agree. All scales were translated to Arabic, then were back translated to check the translation's validity (Brislin, 1986). Pre-testing was conducted to ensure the clarity and understandability of all scales' items. Students voluntarily filled out the survey instruments. No rewards were offered in return.

\section{DATA ANALYSIS}

\section{A. Exploratory factor analysis (EFA)}

An EFA was conducted using Maximum Likehood with promax rotation on the scales' items in order to determine unique variance among items, and to see if the observed variables loaded together as expected and were adequately correlated, and met the criteria of reliability and validity. Maximum Likehood also provides a goodness of fit test for the factor solution. Promax was chosen because the dataset is quite large $(\mathrm{N}=402)$ and promax can account for the correlated factors.

\section{B. Adequacy}

The KMO and Bartlett's test for sampling adequacy was significant (.915) and the communalities for each variable were sufficiently high (all above 0.300 and most above 0.600 ), thus indicating that the variables were adequately correlated. The reproduced matrix had only $2 \%$ non-redundant residuals greater than 0.05 , further confirming the adequacy of the variables.

\section{Validity}

The factors demonstrated sufficient convergent validity as their loadings were all above the recommended minimum threshold of 0.350 for a sample size of 300 (Hair et al, 2010). The factors also demonstrate sufficient discriminant validity, as the correlation matrix demonstrates no correlation above 0.700 , and there are no problematic cross-loadings. The seven-factors had a total variance explained of $67 \%$.

\section{Confirmatory factor analysis}

To further confirm validity and reliability of the results from EFA, a confirmatory Factor Analysis was conducted using Amos. The goodness of fit for the variables extracted from the EFA are sufficient. Factors that had poor loadings were removed from the matrix, and loadings less than $(0.40)$ were omitted to improve clarity.

Table 1. Goodness of fit from the EFA ( $\mathrm{N}=402)$

\begin{tabular}{|c|c|c|}
\hline Metric & Observed Value & Recommended \\
\hline cmin/df & 2.164 & Between 1 and 3 \\
\hline CFL & .933 & $>0.950$ \\
\hline RMSEA & .054 & $<0.60$ \\
\hline PCLOSE & .126 & $>0.050$ \\
\hline SRMR & .055 & $<0.090$ \\
\hline
\end{tabular}

\section{E. Validity and Reliability}

To test for convergent validity the AVE was calculated. For all factors, the AVE was above 0.50. To test for discriminant validity the square root of the AVE on the diagonal to all interfactor correlations were compared. Table 2. All factors demonstrated adequate discriminant validity because the diagonal values are greater than the correlations. The composite reliability for each factor was also computed. In all cases the CR was above the minimum threshold of 0.70 , indicating there is a reliability for each factor.

Table 2. Inter-Construct Correlation $(N=402)$

\begin{tabular}{|c|c|c|c|c|c|c|c|c|c|}
\hline & CR & AVE & CI & TFD & GSE & TID & PG & DEC & II \\
\hline 1. CI & 0.814 & 0.686 & $\mathbf{0 . 8 2 8}$ & & & & & & \\
\hline 2. TFD & 0.904 & 0.516 & 0.485 & $\mathbf{0 . 7 1 9}$ & & & & & \\
\hline 3. GSE & 0.838 & 0.509 & 0.525 & 0.512 & $\mathbf{0 . 7 1 3}$ & & & & \\
\hline 4. TID & 0.816 & 0.528 & 0.648 & 0.591 & 0.465 & $\mathbf{0 . 7 2 7}$ & & & \\
\hline 5. PG & 0.847 & 0.650 & 0.504 & 0.492 & 0.424 & 0.683 & $\mathbf{0 . 8 0 6}$ & & \\
\hline 6. DEC & 0.730 & 0.575 & 0.333 & 0.503 & 0.467 & 0.586 & 0.566 & $\mathbf{0 . 7 5 8}$ & \\
\hline 7. II & 0.717 & 0.559 & 0.442 & 0.402 & 0.628 & 0.514 & 0.369 & 0.303 & $\mathbf{0 . 7 4 8}$ \\
\hline
\end{tabular}

The factors demonstrated adequate discriminant validity because the diagonal values are greater than the correlations. 
Proc. of The Fifirth Intl. Conf. On Advances in Economics, Management and Social Study - EMS 2016

Copyright () Institute of Research Engineers and Doctors, USA .All rights reserved.

ISBN: 978-1-63248-089-7 doi: 10.15224/ 978-1-63248-089-7-37

The composite reliability for each factor was also computed. In all cases the CR was above the minimum threshold of 0.70 , indicating that the extracted factors are reliable. The pattern matrix was re-run. The final CFA results for the seven studyfactors extracted are: Touch and Interpersonal Distance (TID), Direct Eye Contact (DEC), Paralinguistics and Gestures (PG), Tolerance for Disagreement (TFD), General Self-efficacy (GSE), Individualism/ Independent Self-Construal (II), Collectivism/ Interdependent Self-Construal (CI). The weighted averaged standardized composite variables that were used for analysis and the Cronbach's alphas obtained are in Table 3. All alphas were above 0.70 .

Table 3. Confirmatory factor analysis and Cronbach's alpha $(\mathrm{N}=402)$

\begin{tabular}{|c|c|}
\hline \multicolumn{2}{|l|}{ Constructs } \\
\hline TFD & \\
\hline I don't like to be in situations where people are in disagreement. & .786 \\
\hline I prefer being in groups where everyone's beliefs are the same as mine. & .776 \\
\hline I prefer to change the topic of discussion when disagreement occurs. & .738 \\
\hline I enjoy arguing with other people about things on which we disagree. (R) & .702 \\
\hline I would prefer joining a group where no disagreements occur. & .684 \\
\hline I don't like to disagree with other people. & .677 \\
\hline $\begin{array}{l}\text { Given a choice, I would leave a conversation rather than continue a } \\
\text { disagreement. }\end{array}$ & .661 \\
\hline I avoid talking with people who I think will disagree with me. & .655 \\
\hline I enjoy disagreeing with others. (R) & .640 \\
\hline$G S E$ & \\
\hline I can always manage to solve difficult problems if I try hard enough. & .762 \\
\hline If someone opposes me, I can find the means and ways to get what I want. & .745 \\
\hline It is easy for me to stick to my aims and accomplish my goals. & .735 \\
\hline When I am confronted with a problem, I can usually find several solutions. & .707 \\
\hline I can usually handle whatever comes my way. & .684 \\
\hline$P G$ & \\
\hline I use a variety of vocal expressions when I talk to people. & .819 \\
\hline I gesture when I talk to people. & .799 \\
\hline I have a lot of vocal variety when I talk to people. & .753 \\
\hline$T I D$ & \\
\hline I touch others on the shoulder or arm while talking to them. & .791 \\
\hline I move closer to people when I talk to them. & .699 \\
\hline I lean toward people when I talk to them. & .652 \\
\hline I avoid touching people when I talk to them. (R) & .599 \\
\hline II & \\
\hline It is very important for me to act as an independent person. & .816 \\
\hline I enjoy being unique and different from others. & .765 \\
\hline DEC & \\
\hline I avoid eye contact while talking to people. (R) & .752 \\
\hline I maintain eye contact with people when I talk to them. & .748 \\
\hline CI & \\
\hline $\begin{array}{l}\text { I try to meet demands of my group, even if it means controlling my own } \\
\text { desires. }\end{array}$ & .808 \\
\hline I act as fellow group members would prefer me to. & .785 \\
\hline
\end{tabular}

Table 4. Pearson correlation of study variables, Alphas' Means, and Standard Deviations

\begin{tabular}{|c|c|c|c|c|c|c|c|c|c|c|}
\hline Variables & $\boldsymbol{\alpha}$ & $\mathbf{M}$ & $\boldsymbol{S D}$ & $\mathbf{1}$ & $\mathbf{2}$ & $\mathbf{3}$ & $\mathbf{4}$ & $\mathbf{5}$ & $\mathbf{6}$ & $\mathbf{7}$ \\
\hline 1. TFD & .904 & 3.59 & .827 & - & & & & & & \\
\hline 2. GSE & .837 & 3.94 & .716 & $.450 * *$ & - & & & & & \\
\hline 3. TID & .856 & 2.99 & 1.03 & $.493 * *$ & $.390^{* *}$ & - & & & & \\
\hline 4. DEC & .728 & 3.91 & .936 & $.400 * *$ & $.372 * *$ & $.455^{* *}$ & - & & & \\
\hline 5. PG & .844 & 3.62 & 1.00 & $.431 * *$ & $.363 * *$ & $.568 * *$ & $.452 * *$ & - & & \\
\hline 6. CI & .807 & 3.59 & 1.14 & $.412 * *$ & $.438 * *$ & $.525 * *$ & $.258 * *$ & $.421 * *$ & - & \\
\hline
\end{tabular}

\section{II $\quad .817|4.04| .887\left|.313^{* *}\right| .481 * *|.397 * *| .213^{* *}|.293 * *| .346 * * \mid-$}

Note. **. Correlation is significant at the 0.01 level (2-tailed).

\section{DATA ANALYSIS AND RESULTS}

Regression analysis and the (Baron \& Kenny, 1986) approach and Sobel test was used to test the research hypotheses. For research hypothesis one, regression analysis was conducted to investigate how well the dependent communication variables TID, DEC, PG and TFD can be predicted from the Independent self-construal. Results indicate that there is a main effect for the Independent self-construal variable on TID $F(1,400)=74.662$; DEC $F(1,400)=18.984$; PG $F(1,400)=37.611$; and for TFD $F(1,400)=43.594$. The effect of the Interdependent self-construal variable on TID $F$ $(1,400)=152.279 ;$ DEC $F(1,400)=28.427$; PG $F(1,400)=$ 86.292; and for TFD $F(1,400)=81.910$. Table 5. Thus, indicating that there is a lower effect for individuals who perceive an Independent self-construal on TID, DEC, PG and TFD communication behavior than those who perceive an Interdependent self-construal. Research hypothesis $\mathrm{H}$ : 1 is sustained.

Next, for $\mathrm{H} 2$ and $\mathrm{H} 3$ to analyze whether GSE will mediate the effect of the Independent self-construal, the Interdependent self-construal and TID, DEC, PG, TFD behavior. First, to avoid potentially problematic high multicollinearity with the interaction terms, the Independent self-construal (II) and the Interdependent self-construal (CI) variables were centered and interaction terms between (II x GSE) and (CI x GSE) were created (Aiken \& West, 1991). Next, the interaction terms were added to the regression model for each separate analysis. A four step regression mediation model was conducted for each analysis separately. In the first step of the mediation model the regression of the independent variable on the dependent variable, ignoring the mediator should also be significant. Step 2 should indicate that the regression of the independent variable on the mediator is significant. Step 3 of the mediation process must indicate that the mediator controlling for depended variable is significant. Step four of the analysis should indicate that controlling for the mediator, the dependent variable is still a significant predictor of the independent variable. All results are in Table 5.

Table 5. Mediation effect of GSE on communication variables

\begin{tabular}{|c|c|c|c|c|c|c|}
\hline $\begin{array}{c}\text { Regression } \\
\text { step }\end{array}$ & $\mathbf{R}^{2}$ & $\begin{array}{c}\mathbf{R}^{2} \\
\text { change }\end{array}$ & $b$ & $\boldsymbol{\beta}$ & $\mathbf{t}$ & $\mathbf{P}$ \\
\hline \multicolumn{7}{|c|}{ Mediation effect of GSE on the relationship between II and TID } \\
\hline (1) TID - II & .157 & & .459 & .397 & $(400)=8.641$ & $* * *$ \\
\hline (2) GSE - II & .535 & & .388 & .481 & $(400)=10.967$ & \\
\hline (3) TID-GSE & .152 & & .371 & .259 & $(399)=5.095$ & $* * *$ \\
\hline (4) TID - II & .209 & .057 & .315 & .272 & $(399)=5.360$ & $* * *$ \\
\hline \multicolumn{7}{|c|}{ Mediation effect of GSE on the relationship between CI and TID } \\
\hline (1) TID -CI & .276 & & .475 & .525 & $(400)=12.340$ & $* * *$ \\
\hline (2) GSE- CI & .192 & & .276 & .438 & $(400)=9.735$ & $* * *$ \\
\hline (3) CI - GSE & .152 & & .284 & .198 & $(399)=4.266$ & \\
\hline (4) TID - CI & .307 & .156 & .397 & .439 & $(399)=9.464$ & $* * *$ \\
\hline \multicolumn{7}{|c|}{ Mediation effect of GSE on the relationship between the II and DEC } \\
\hline (1) DEC - II & .045 & & .225 & .213 & $(400)=4.357$ & $* * *$ \\
\hline (2) GSE - II & .231 & & .388 & .481 & $(400)=10.967$ & $* * *$ \\
\hline (3) DEC-GSE & .139 & & .459 & .351 & $(399)=6.633$ & $* * *$ \\
\hline
\end{tabular}


Proc. of The Fifirth Intl. Conf. On Advances in Economics, Management and Social Study - EMS 2016

Copyright (C) Institute of Research Engineers and Doctors, USA .All rights reserved. ISBN: 978-1-63248-089-7 doi: 10.15224/ 978-1-63248-089-7-37

\begin{tabular}{|c|c|c|c|c|c|c|}
\hline $\begin{array}{c}\text { Regression } \\
\text { step }\end{array}$ & $\mathbf{R}^{2}$ & $\begin{array}{c}\mathbf{R}^{2} \\
\text { change }\end{array}$ & $b$ & $\boldsymbol{\beta}$ & $\mathbf{t}$ & $\mathbf{P}$ \\
\hline (4) $\mathrm{DEC}-\mathrm{II}$ & .140 & .001 & .046 & .044 & $(399)=.831$ & $(\mathrm{~ns})=.406$ \\
\hline \multicolumn{7}{|c|}{ Mediation effect of GSE on the relationship between CI and DEC } \\
\hline (1) DEC-CI & .066 & & .212 & .258 & $(400)=5.332$ & $* * *$ \\
\hline (2) GSE- CI & .192 & & .276 & .438 & $(400)=9.735$ & $* * *$ \\
\hline (3) CI - GSE & .139 & & .420 & .321 & $(399)=6.254$ & $* * *$ \\
\hline (4) DEC-CI & .150 & .011 & .096 & .117 & $(399)=2.280$ & $*$ \\
\hline \multicolumn{7}{|c|}{ Mediation effect of GSE on the relationship between the II and PG } \\
\hline (1) PG - II & .086 & & .333 & .293 & $(400)=6.133$ & $* * *$ \\
\hline (2) GSE - II & .231 & & .388 & .481 & $(400)=10.967$ & \\
\hline (3) PG - GSE & .132 & & .405 & .289 & $(399)=5.484$ & $* * *$ \\
\hline (4) PG - II & .150 & .018 & .175 & .154 & $(399)=2.933$ & $* *$ \\
\hline \multicolumn{7}{|c|}{ Mediation effect of GSE on the relationship between CI and PG } \\
\hline (1) $\mathrm{PG}-\mathrm{CI}$ & .177 & & .373 & .421 & $(400)=9.289$ & $* * *$ \\
\hline (2) GSE- PG & .192 & & .276 & .438 & $(400)=9.735$ & \\
\hline (3) CI - GSE & .132 & & .310 & .221 & $(399)=4.482$ & $* * *$ \\
\hline (4) $\mathrm{PG}-\mathrm{CI}$ & .217 & .085 & .288 & .325 & $(399)=6.588$ & \\
\hline \multicolumn{7}{|c|}{ Mediation effect of GSE on the relationship between the II and TFD } \\
\hline (1) TFD - II & .098 & & .293 & .313 & $(400)=6.603$ & $* * *$ \\
\hline (2) GSE - II & .231 & & .388 & .481 & $(400)=10.967$ & $* * *$ \\
\hline (3) TFD-GSE & .202 & & .449 & .389 & $(399)=7.682$ & $* * *$ \\
\hline (4) TFD - II & .214 & .012 & .118 & .127 & $(399)=2.501$ & $*$ \\
\hline \multicolumn{7}{|c|}{ Mediation effect of GSE on the relationship between CI and TFD } \\
\hline (1) TFD -CI & .170 & & .300 & .412 & $(400)=9.050$ & $* * *$ \\
\hline (2) GSE-TFD & .192 & & .276 & .438 & $(400)=9.735$ & $* * *$ \\
\hline (3) CI - GSE & .202 & & .385 & .333 & $(399)=6.950$ & $* * *$ \\
\hline (4) TFD - CI & .260 & .057 & .194 & .267 & $(399)=5.564$ & $* * *$ \\
\hline
\end{tabular}

Note. $* p<.05 . * * p<.005 . * * * p<.001$.

Results of Sobel test showed that GSE partially mediated the relationship between II and TID behavior, $\mathrm{z}=4.619, P=$ 004. Fig1.

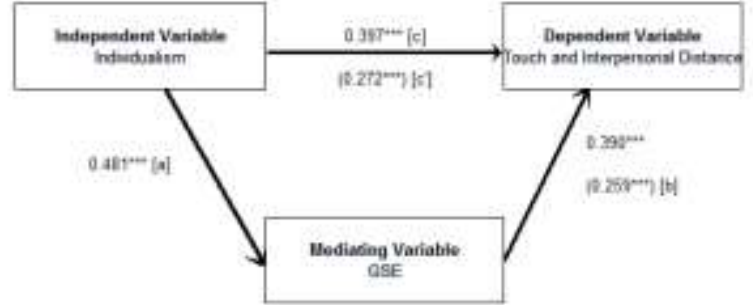

Figure 1. GSE partially mediated the relationship between II and TID

GSE partially mediated the relationship between CI and TID behavior. Table 5. Sobel test, $\mathrm{z}=3.4936, \mathrm{P}=008$. Fig 2 .

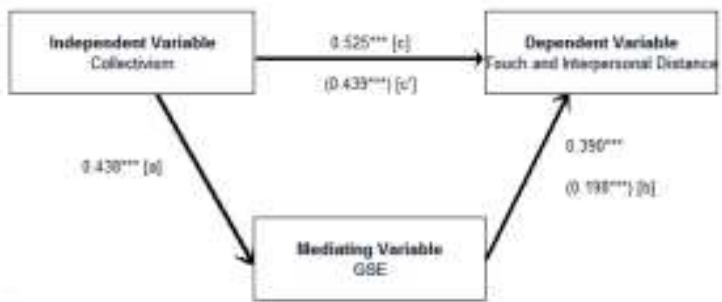

Figure 2. GSE partially mediated the relationship of CI and TID

The mediation effect of GSE on the relationship between II and DEC behavior was significant. Controlling for the mediator, II was not a significant predictor of DEC behavior, $\mathrm{b}=.046, \mathrm{p}=.406$. Table 5. Sobel test indicates that GSE fully mediated the relationship between the II and DEC behavior $\mathrm{z}=$ 5.704, $\mathrm{p}<.001$. Fig 3 .

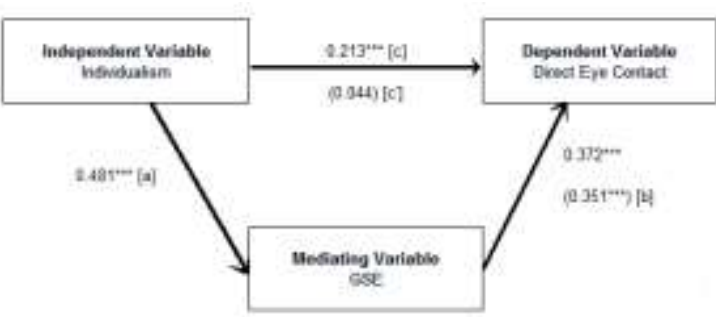

Figure 3. GSE fully mediated the relationship of II and DEC

GSE partially mediated the relationship between CI and DEC behavior. Table 5. Sobel test, $\mathrm{z}=5.289, \mathrm{p}<.001$. Fig 4.

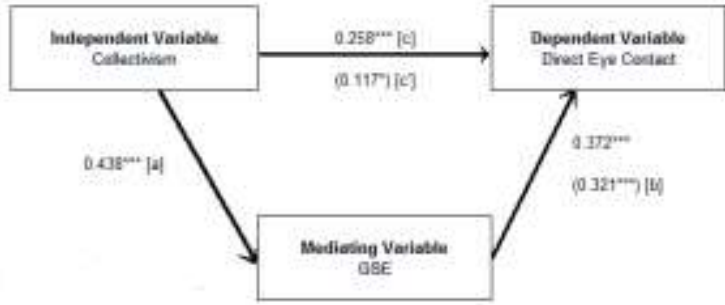

Figure 4. GSE partially mediated the relationship of CI and DEC

GSE partially mediated the relationship between II and PG behavior. Table 5. Sobel test $\mathrm{z}=4.907, \mathrm{P}<.001$. Fig 5 .

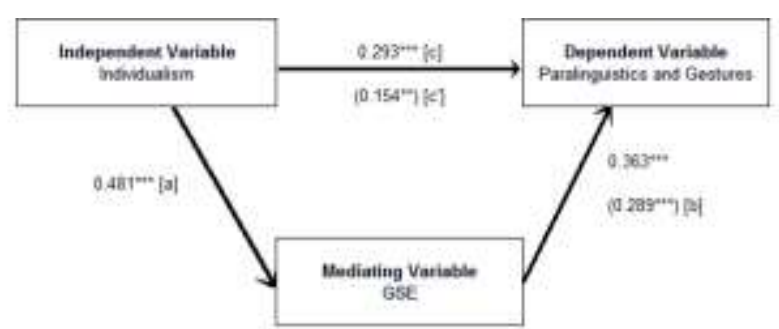

Figure 5. GSE partially mediated the relationship of II and PG

GSE partially mediated the relationship between CI and PG behavior. Table 5. Sobel test, $\mathrm{z}=4.08813, \mathrm{P}=004$. Fig 6 .

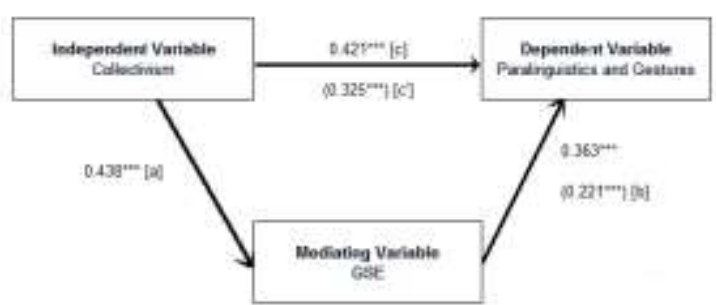

Figure 6. GSE partially mediated the relationship of CI and PG

GSE partially mediated the relationship between II and TFD behavior. Table 5. Sobel test, $\mathrm{z}=6.347, \mathrm{P} \leq .001$. Fig 7 . 


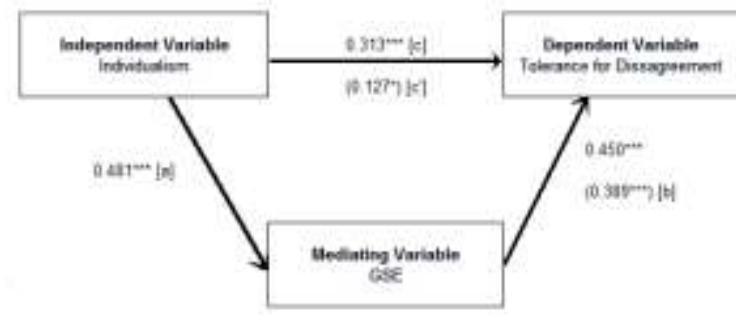

Figure 7. GSE partially mediated the relationship of II and TFD

GSE partially mediated the relationship between CI and TFD behavior. Table 5. Sobel test $\mathrm{z}=5.707, \mathrm{P}<.001$. Fig 8 .

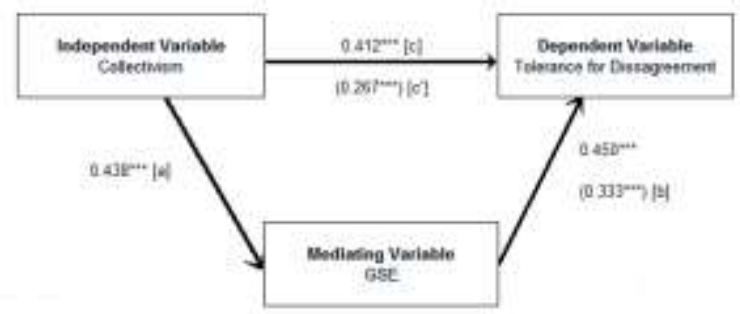

Figure 8. GSE partially mediated the relationship of CI and TFD

Based on the above results, hypotheses $\mathrm{H}: 1$ and $\mathrm{H}: 2$ are sustained.

\section{DISCUSSION}

Results indicated that GSE affected TID, DEC, PG and TFD behavior. This is similar to past study results that found perceived self-efficacy helps individuals to feel, think, and act (Armitage, Conner, Loach \& Willets, 1999; Bandura, 1995; 1997; Fan \& Mak, 1998; Griffiths, 2007; Kim \& Omizo, 2005; Klassen, 2004; Kumar \& Lal, 2006; Luszczynska \& Schwarzer, 2005; Scholz et al, 2002; Schwarzer \& Fuchs, 1996; Schwarzer \& Jerusalem, 1995). However, the predictive power of GSE beliefs differed according to the perceived independent and interdependent self-construal an individual perceives within the same culture, indicating that perceived efficacy expectations, do not operate as dispositional determinants independently of contextual factors (Bandura, 1977), where culture plays an influential role in forming personal efficacy beliefs (Oettingen, 1995), and that how individuals perceive their efficacy is developed and derived from the value system which is influenced by several different environmental factors in a given culture (Inkeles \& Levinson, 1969). Results of this study indicate that GSE reduced the impact of culture on TID, DEC, PG and TFD communication behavior variables to different extents within individuals of a collectivist culture confirming that interdependence does not obliterate a personal self (Bandura, 1997, 2002) and explaining why considerable variation could exists within individuals from the same cultural group (Sinha \& Tripathi, 1994). The result that the interdependent self-construal cultural variable had a higher effect than the independent self-construal on the TID, DEC, PG and TFD behavior within a collectivist culture can be a result of the impact of culture on individuals where independent behavior is suppressed, and common communication patterns are imposed among individuals (Hofstede, 1980, 1991). Individuals in collectivist cultures pursue goals that comply more with the needs of their in-group rather than their own needs and levels of individual competence (Ames, 1992; Dweck \& Leggett, 1988; Hall, 1966, 1973; Nydell, 1987; Yousef, 1974; Khalid, 1977). However, the result that the independent self-construal had an impact on TID, DEC, PG and TFD behavior within a collectivist culture implies that individuals of the same culture perceive national cultural values to different degrees (Hofstede, 1984), and further indicates that individuals with a perceived independent self-construal have a lower connection between the self and others (Straub et al, 2002). Moreover, it explains how individual behavior is a mixture of personal and behavioral environmental factors (Bandura, 1986) where an individual may belong to a cultural group and at the same time possess multiple cultural identities (Straub et al, 2002). Results of this study indicate that the evaluative nature of self-beliefs make them play the role of a filter or a mediator for subsequent behavior and that an individual's judgment of self-efficacy mediates the effects of other determinants of behavior (Abelson, 1979; Calderhead \& Robson, 1991; Dewey, 1993; Goodman, 1988; James, 1988; Mead, 1982; Nisbett \& Ross, 1980; Pajares, 1992). Therefore, rejecting the notion that selfefficacy plays a less important role in collectivist cultures (Bandura, 1997, 2002), and acknowledging that individuals in collectivist settings vary considerably. Results of this study are similar to the results of a study by Lomeranz (1976) of interaction distances of Iraqi, Argentinian and Russian students that found significant differences within samples of contact cultures.

\section{Conclusions and future research}

Culture was found a critical factor in determining individual perceptions of efficacy as well as communication behavior responses (Biglan, 1987). Self-efficacy mediated individual communication behavior (Biglan \& Kass, 1977; Moore, 1984a, 1984b; Skinner, 1953; Zettle \& Hayes, 1982). Thus, implying, that from a practical perspective, the communication behavioral patterns of individuals and societies can be changed (Bandura, 1971; Flanders, 1968) by improving self-efficacy through training and learning (Gist and Mitchell, 1992). Results indicate that there is a need to redefine and further differentiate cultural concepts through research. Future studies should examine the study constructs with other nonArab samples and contexts. Further studies on other communication behaviors are recommended. In addition, future studies should examine the impact of Islam on individual communication behavior.

\section{REFERENCES}

[1] R. ABELSON, "Differences between belief and knowledge systems," Cognitive Science, vol. 3, pp. 355-366, 1979.

[2] A. J. Almaney and A. J. Alwan, Communicating with the arabs. A handbook for the business executive. Prospect heights, ill.: Waveland Press, 1982

[3] C. Ames, "Classrooms: Goals, structures, and student motivation," Journal of Educational Psychology, vol. 84, no. 3, pp. 261271, 1992.

[4] C. J. Armitage, M. Conner, J. Loach, and D. Willetts, "Different perceptions of control: Applying an extended theory of planned behavior to legal and illegal drug use," Basic and Applied Social Psychology, vol. 21 , no. 4, pp. 301-316, 1999 
[5] A. Bandura and A. Ura, Self-efficacy: The exercise of control. New York, NY: W.H.Freeman \& Co, 1997.

[6] A. Bandura, Principles of behaviour modification. New York: Holt, Rinehart and Winston, 1969

[7] A. Bandura, Psychological modeling. Chicago: Chicago, AldineAtherton, 1971.

[8] A. Bandura, "Self-efficacy: Toward a unifying theory of behavioral change," Psychological Review, vol. 84, no. 2, pp. 191-215, 1977

[9] A. Bandura, "Recycling misconceptions of perceived selfefficacy," Cognitive Therapy and Research, vol. 8, no. 3, pp. 231-255, Jun. 1984

[10] A. Bandura, Social foundations of thought and action: A social cognitive theory. Englewood Cliffs, NJ: Prentice-Hall, 1986

[11] A. Bandura, "Social cognitive theory in cultural context," Journal of Applied Psychology, vol. 51, no. 2, pp. 269-290, 2002

[12] A. B, Self-efficacy in changing societies. New York: Cambridge University Press, 1995

[13] J. D. Boucher and G. E. Carlson, "Recognition of facial expression in Three cultures," Journal of Cross-Cultural Psychology, vol. 11, pp. 263280,1980

[14] M. Burgoon, J. K. Heston, and J. McCroskey, Small group communication: A functional approach. New York: Holt, Rinehart and Winston, 1974.

[15] J. Calderhead and M. Robson, "Images of teaching: Student teachers' early conceptions of classroom practice," Teaching and Teacher Education, vol. 7, pp. 1-8, 1991 .

[16] H. Cho, J. So, and J. Lee, "Personal, social, and cultural Correlates of self-efficacy beliefs among south Korean college smokers," Health Communication, vol. 24, no. 4, pp. 337-345, 2009

[17] R. Cohen, "Problems of intercultural communication in EgyptianAmerican diplomatic relations,"International Journal of Intercultural Relations, vol. 11, pp. 29-47, 1987

[18] M. J. Collier, "Cultural and intercultural communication competence: Current approaches and directions for future research," International Journal of Intercultural Relations, vol. 13, pp. 287-302, 1989

[19] C. R. Cooper and J. Denner, "THEORIES LINKING CULTURE AND PSYCHOLOGY: Universal and community-specific processes," Аппиаl Review of Psychology, vol. 49, pp. 559-584, 1998

[20] K. Deaux, "Reconstructing social identity," Personality and Social Psychology Bulletin, vol. 19, pp. 4-12, 1993

[21] J. Dewey, How we think. Boston: D.C. Health, 1993

[22] C. S. Dweck and E. L. Leggett, "A social-cognitive approach to motivation and personality", Psychological Review, vol. 95, no. 2, pp. 256-273, 1988

[23] P. Ekman, Darwin and facial expression: A century of research in review. New York: Academic Press, 1974.

[24] P. Ekman and W. V. Friesen, "The repertoire of nonverbal behavior: Categories, origins, usage, and coding," Semiotica, vol. 1, pp. 49-98, 1969

[25] P. Ekman and W. V. Friesen, Unmasking the face: A guide to recognizing emotions from facial clues. Englewood Cliffs, NJ: Prentice Hall, 1975

[26] H. A. Elfenbein and N. Ambady, "Cultural similarity's consequences: A distance perspective on cross-cultural differences in emotion recognition," Journal of Cross-Cultural Psychology, vol. 34, pp. 92110,2003

[27] C. Fan and A. S. Mak, Measuring social self-efficacy in a culturally diverse student population," Social Behavior and Personality: an international journal, vol. 26, no. 2, pp. 131-144, 1998.

[28] E. Feghali, "Arab cultural communication patterns," International Journal of Intercultural Relations, vol. 21, no. 3, pp. 345-378, 1997

[29] J. P. FLANDERS, "A review of research on imitative behavior," Psychological Bulletin, vol. 69, no. 5, pp. 316-337, 1968

[30] M. E. Gist and T. R. Mitchell, "Self-efficacy: A theoretical analysis of its determinants and Malleability," The Academy of Management Review, vol. 17, no. 2, pp. 183-211, 1992

[31] J. Goodman, "Constructing a practical philosophy of teaching: A study of preservice teachers' professional perspectives," Teaching and Teacher Education, vol. 4, no. 2, pp. 121-137, 1988

[32] W. B. Gudykunst and Y. Y. Kim, Communicating with strangers: An approach to Intercultural communication. New York: Mcgraw Hill, 1984

[33] William B Gudykunst, Stella Ting-Toomey, Culture and interpersonal communication. Newbury Park, CA: SAGE Publications, 1988

[34] E. T. T. Hall, The hidden dimension. New York: Doubleday, 1966

[35] E. T. T. Hall, The silent language. New York: Anchor, 1973

[36] G. Hofstede, Culture's consequences: International differences in workrelated values. Beverly Hills, CA US: Sage Publications, 1980

[37] G. Hofstede, Culture's consequences. Beverly Hills, CA: Sage Publications, 1984

[38] G. Hofstede, Cultures and organizations: Software of the mind Intercultural cooperation and its importance for survival. New York, NY US: McGraw-Hill, 1991

[39] W. James, Pragmatism. Cambridge, MA: Harvard University Press, 1988

[40] J. E. Kilbride and M. Yarczower, "Ethnic bias in the recognition of facial expressions," Journal of Nonverbal Behavior, vol. 8, pp. 27-41, 1983

[41] B. S. K. Kim and M. M. Omizo, "Asian and European American cultural values, collective self-esteem, Acculturative stress, cognitive flexibility, and general self-efficacy among Asian American college students," Journal of Counseling Psychology, vol. 52, pp. 412-419, 2005

[42] J. C. Kimball, The Arabs 1984/85. Washington, DC: American Educational Trust, 1984

[43] R. M. Klassen, "Optimism and realism: A review of self-efficacy from a cross-cultural perspective," International Journal of Psychology, vol. 39, no. 3, pp. 205-230, 2004

[44] J. B. Koch, "Presentation as proof. The language of Arabic rhetoric," Anthropological Linguistics, vol. 25, no. 1, pp. 47-60, 1983

[45] R. Kumar and R. Lal, "The Role of Self-Efficacy and Gender Differences among the Adolescents,"Journal of the Indian Academy of Applied Psychology, vol. 32, no. 3, pp. 345-350, 2006

[46] T. Leung and M.S. Kim, A revised self-construal scale. Honolulu: University of Hawaii at Manoa, 1997.

[47] R. W. Levenson, P. Ekman, K. Heider, and W. V. Friesen, "Emotion and autonomic nervous system activity in the Minangkabau of west Sumatra," Journal of Personality and Social Psychology, vol. 62, pp. 972-988, 1992.

[48] T. W. Lippman, Understanding Islam: An introduction to the Muslim world (Revised Ed). New York: Mentor, 1990

[49] J. Lomranz, "Cultural variations in personal space," The Journal of Social Psychology, vol. 99, no. 1, pp. 21-27, 1976

[50] R. Markham and L. Wang, "Recognition of emotion by Chinese and Australian children," Journal of Cross-Cultural Psychology, vol. 27, pp. 616-643, 1996

[51] H. R. Markus and S. Kitayama, "Culture and the self: Implications for cognition, emotion, and motivation," Psychological Review, vol. 98, pp. 224-253, 1991

[52] R. C. Martin, Islam: A Cultural Perspective. Englewood Cliffs, NJ: Prentice Hall.: Prentice Hall, 1982

[53] D. Matsumoto, "Cultural influences on the perception of emotion," Journal of Cross-Cultural Psychology, vol. 20, pp. 92-105, 1989

[54] D. Matsumoto, S. H. Yoo, S. Hirayama, and G. Petrova, "Development and validation of a measure of display rule knowledge: The display rule assessment inventory," Emotion, vol. 5, pp. 23-40, 2005.

[55] J. C. McCroskey, An introduction to communication in the classroom. Edina, MN: Burgess International, 1992

[56] J. C. McCroskey and Wheeless, An introduction to human communication. Boston, MA: Allyn \& Bacon, 1976

[57] G. H. Mead, The individual and the social self. Chicago: University of Chicago Press, 1982

[58] A. Mehrabian, "Some referents and measures of nonverbal behavior," Behavior Research Methods \& Instrumentation, vol. 1, pp. 213-217, 1969

[59] A. Mehrabian, Silent messages: Implicit communication of emotions and 
attitudes, 2nd ed. Belmont: CA: Wadsworth, 1981

[60] W. Minggang and C. Yuan, "A review of cross-cultural researches on the relationship of thinking and language," Psychological Science (China), vol. 27, no. 2, pp. 431-433, 2004

[61] E. Mishler, "Meaning in context: Is there any other kind?," Harvard Educational Review, vol. 49, no. 1, pp. 1-19, 1979

[62] J. Moore, "On behaviorism, knowledge, and causal explanation," The Psychological Record, vol. 34, pp. 73-97, 1984

[63] J. Moore, "On privacy, causes, and contingencies," The Behavior Analyst, vol. 7, pp. 3-16, 1984

[64] Trevor Mostyn, Albert Hourani, The Cambridge encyclopedia of the middle east and north Africa. Cambridge: Cambridge University Press, 1988

[65] G. L. Nelson, W. E. Bakary, and M. A. Batal, "Egyptian and American compliments: A cross-cultural study," International Journal of Intercultural Relations, vol. 17, no. 3, pp. 293-313, 1993

[66] J. W. Neuliep, Intercultural communication: A contextual approach, 4th ed. London, England: SAGE Publications, 2009

[67] R. E. Nisbett and L. Ross, Human inference: Strategies and shortcomings in social judgement. Englewood Cliffs, NJ: Prentice-Hall, 1980

[68] M. K. Nydell, Understanding Arabs: A guide for Westerners. Yarmouth, ME: Intercultural Press, 1987

[69] F. Pajares, "Teachers' beliefs and educational research: Cleaning up a messy construct," Review of Educational Research, vol. 62, pp. 307332, 1992

[70] F. Pajares, "Seeking a culturally attentive educational psychology," Paper presented at the meeting of the American Educational Research Association, 2000

[71] R. Patati, The Arab mind (Revised Ed). New York: Charles Scribner's Sons, 1983

[72] V. P. Richmond, J. C. McCroskey, and A. E. Johnson, "Development of the nonverbal immediacy scale (NIS): Measures of self-and other-perceived nonverbal immediacy," Communication Quarterly, vol. 51, pp. 502-515, 2003

[73] V. P. Richmond and J. C. McCroskey, Organizational communication for survival. Engelwood Cliffs, NJ: Prentice Hall, 1992

[74] A. B. Rugh, Reveal and conceal: Dress in contemporary Egypt. Cairo: American University in Cairo Press, 1986

[75] M. Safadi and C. A. Valentine, "Contrastive analyses of American and Arab nonverbal and paralinguistic communication," Semiotica, vol. 82, no. $3-4,1990$

[76] L. A. Samovar and R. E. Porter, Communication between cultures. Belmont, CA: Wadsworth Publishing Co, 1991

[77] J. L. Sanders, U. M. Hakky, and M. M. Brizzolara, "Personal space amongst Arabs and Americans,"International Journal of Psychology, vol. 20, no. 1, pp. 13-17, 1985

[78] U. Scholz, B. Gutiérrez Doña, S. Sud, and R. Schwarzer, "Is general self-efficacy a universal construct? Psychometric findings from 25 countries," European Journal of Psychological Assessment, vol. 18, no. 3, pp. 242-251, 2002

[79] R. Schwarzer and A. Born, "Optimistic self-beliefs: Assessment of general perceived self-efficacy in thirteen cultures," World Psychology, vol. 3, pp. 1-2, 1997

[80] M. Sherer, J. E. Maddux, B. Mercadente, S. Prentice-Dunn, B. Jacobs, and R. W. Rogers, "The Self-efficacy Scale: Construction and Validation," Psychological Reports, vol. 51, no. 2, pp. 663-671, 1982

[81] E. Shouby, "The influence of the Arabic language on the psychology of the Arabs," Middle East Journal, vol. 5, pp. 298-299, 1951

[82] R. Shuter, "The centrality of culture," Southern Communication Journal, vol. 55 , pp. $237-249,1990$

[83] B. F. Skinner, Science and human behaviour. New York: Macmillan, 1953

[84] E. A. Skinner, M. Chapman, and P. B. Baltes, "Control, means-ends, and agency beliefs: A new conceptualization and its measurement during childhood," Journal of Personality and Social Psychology, vol. 54, no. 1, pp. 117-133, 1988

[85] D. Straub, K. Loch, R. Evaristo, E. Karahanna, and M. Srite, "Toward a theory-based measurement of culture," Journal of Global Information Management, vol. 10, no. 1, pp. 13-23, 2002

[86] J. J. Teven, J. C. McCroskey, and V. P. Richmond, "Measurement of tolerance for disagreement,"Communication Research Reports, vol. 15, pp. 209-217, 1998

[87] H. C. C. Triandis, Individualism and Collectivism. Boulder, CO Westview Press, 1995

[88] H. C. Triandis, "The psychological measurement of cultural syndromes," American Psychologist, vol. 51, pp. 407-415, 1996

[89] J. L. Tsai and R. W. Levenson, "Cultural influences on emotional responding: Chinese American and European American dating couples during interpersonal conflict," Journal of Cross-Cultural Psychology, vol. 28, pp. 600-625, 1997.

[90] M. O. Watson, Proxemic behavior: Cross-cultural study. The Hague: Mouton De Gruyter, 1970

[91] O. M. Watson and T. D. Graves, "Quantitative research in Proxemic behavior," American Anthropologist, vol. 68, pp. 971-985, 1966

[92] F. Yousef, "Cross-cultural communication: Aspects of Contrastive social values between north Americans and middle Easterners," Human Organization, vol. 33, no. 4, pp. 383-387, 1974

[93] R. D. Zettle and S. C. Hayes, "Rule-governed behavior. A potential theoretical framework for cognitive-behavioral therapy," Advances in Cognitive-Behavioral Research and Therapy, vol. 1, pp. 73-118, 1982

[94] S. W. Suleiman, "The Arabs and the West: Communication gap," in Intercommunication among nations and peoples, M. W. Prosser, Ed. New York: Harper \& Row, 1973, pp. 287-303

[95] D. Sinha and R. C. Tripathi, "Individualism in a collectivist culture: A case of coexistence of opposites," in Individualism and collectivism: Theory, methods and applications, U. Kim, H. C. Triandis, C. Kagitcibasi, S. C. Choi, and G. Yoon, Eds. Thousand Oaks, CA: Sage, 1994, pp. 123-137

[96] R. Schwarzer and M. Jerusalem, "Generalized Self-Efficacy Scale," in Measures in health psychology: A user's portfolio. Casual and control beliefs, J. Weinman, S. Wright, and M. Johnston, Eds. Windsor, UK: NFER-NELSON, 1995, pp. 35-37

[97] R. Schwarzer and R. Fuchs, "Self-efficacy and health behaviours," in Predicting health behaviour: Research and practice with social cognition models, M. Connor and P. Norman, Eds. Maidenhead, BRK England: Open University Press, 1996, pp. 163-196

[98] V. P. Richmond, J. C. McCrorskey, and J. S. Gorham, "The relationship between selected immediacy behaviors and cognitive learning," in Communication Yearbook 10, M. McLaughlin, Ed. Beverly Hills, CA: Sage, 1987, pp. 574-590

[99] F. Pajares, "Current directions in self -efficacy research," in Advances in motivation and achievement, M. Maehr and P. R. Pintrich, Eds. Greenwich, CT: JAI Press, 1996, pp. 1-49

[100] G. Oettingen, "Cross-cultural perspectives on self-efficacy," in Selfefficacy in changing societies, A. Bandura, Ed. New York: Cambridge University Press, 1995 , pp. 149-176

[101] A. Luszczynska and R. Schwarzer, "Social cognitive theory," in Predicting health behaviour, 2nd ed., M. Conner and P. Norman, Eds. Buckingham, England: Open University Press, 2005, pp. 127-169

[102] M. Khalid, "The sociocultural determinants of Arab diplomacy," in Arab and American cultures, G. N. Atiyeh, Ed. Washington DC: American Enterprise Institute for Public Policy Research, 1977, pp. $123-142$

[103] A. Inkeles and D. J. Levinson, "National character: The study of model personality and sociocultural systems," in The handbook of social psychology IV, G. Lindzey and E. Aronson, Eds. New York, NY US: McGraw Hill, 1969, pp. 418-506

[104] J. H. Griffiths, "Academic self-efficacy, career self-efficacy, and psychosocial identity development: A comparison of female college students from differing socioeconomic status groups," Dissertation Abstracts International: The humanities and social sciences, vol. 67, pp. 28-92, 2007

[105] EENI Business School, "Muslim population by countries: Indonesia Saudi Arabia," 1995-2015. [Online]. Available: http://en.reingex.com/Muslim-population-countries.asp 
Proc. of The Fifirth Intl. Conf. On Advances in Economics, Management and Social Study - EMS 2016

Copyright (C) Institute of Research Engineers and Doctors, USA .All rights reserved.

ISBN: 978-1-63248-089-7 doi: 10.15224/ 978-1-63248-089-7-37

[106] R. J. Davidson, "Parsing the subcomponents of emotions and disorders of emotion: Perspectives from affective neuroscience," in Handbook of affective sciences, R. J. Davidson, K. R. Scherer, and H. H. Goldsmith, Eds. New York: Oxford University Press, 2003, pp. 8-24

[107] M. J. Collier and M. Thomas, "Cultural identity: An interpretive perspective," in Theories in intercultural communication, Y. Y. Kim and W. B. Gudykunst, Eds. Newbury Park, CA: Sage, 1988, pp. 99-120

[108] A. Biglan, "A behavior-analytic critique of Bandura's self-efficacy theory," The Behavior Analyst, vol. 10, no. 1, pp. 1-15, 1987

[109] A. Biglan and D. J. Kass, "The empirical nature of behavior therapies," Behaviorism, vol. 5, pp. 1-15, 1977

[110] A. Bandura, Social foundations of thought and action: A social cognitive theory. Englewood Cliffs, NJ US: Prentice Hall, Inc, 1986

[111]A. Bandura, "Self-efficacy," in Encyclopedia of human behavior, V. S Ramachaudran, Ed. New York: Academic Press, 1994, pp. 71-81 